Al Maal : Journal of Islamic Economics and Banking

http://jurnal.umt.ac.id/index.php/jieb

E-ISSN : $\quad 2580-3816$

Vol : 3 No. 1 Bulan Juli Tahun 2021

Hlm : $84-92$

DOI : $\quad$ : 10.31000/almaal.v3i1.4551

\title{
Analisis Manajemen Pengelolaan Wakaf Masjid Raodhatul Jannah Kelurahan Jene Tallasa Kabupaten Gowa
}

\author{
Trisno Wardy Putra ${ }^{1 *}$, Ahmad Mahdi Bunayya ${ }^{2}$ \\ 1,2, Prodi Ekonomi Islam, Fakultas Ekonomi dan Bisnis Islam, Universitas Islam Negeri \\ Alauddin Makassar, Indonesia \\ *trisno.putra@uin-alauddin.ac.id
}

\begin{abstract}
This study seeks to provide an overview of the management of waqf management at the Raodhatul Jannah mosque, Jene Tallasa Village, Gowa Regency. The not yet certified waqf land can jeopardize the donated land in the future. The quality of human resources for managing mosques is also lacking in quality in developing waqf assets to be more productive. This study aims to provide an overview to the parties involved, in this case waqf, regarding the nature of waqf in Indonesia which has been unproductive and many have not been certified as a consideration for increasing the use of waqf assets in the future. This type of research is descriptive qualitative. The result of this research is the problematic management of waqf in Raodhatul Jannah mosque lies in the land of waqf which is not yet certified due to inevitable obstacles. Most of the mosque managers only run religious and social programs and have not focused on developing waqf assets in a more productive direction.
\end{abstract}

Keywords: Waqf; Management; Productive.

\begin{abstract}
ABSTRAK
Penelitian ini berupaya memberikan gambaran tentang manajemen pengelolaan wakaf di masjid Raodhatul Jannah KelurahanJene Tallasa, Kabupaten Gowa. Belum tersertifikasinya tanah wakafdapat membahayakan harta wakaf dikemudian hari. Kualitas SDM pengelola masjid juga masih kurang berkualitas dalam mengembangkan harta wakaf menjadi lebih produktif.Penelitian inibertujuan untuk memberikan gambaran kepada pihak-pihak yang terkait dalam hal ini wakaf, mengenai sifat wakaf di Indonesia yang selama ini tidak produktif dan banyak yang belum tersertifikasi menjadi pertimbangan untuk peningkatan pemanfaatan harta wakaf di masa depan. Jenis penelitian bersifat deskriptif kualitatif. Hasil dari penelitian ini adalah problematika pengelolaan wakaf di masjid Raodhatul Jannah terletak pada tanah wakafnya yang masih belum memiliki sertifikat karena adanya kendala yang tidak bisa dihindari. Pengelola masjid kebanyakan hanya menjalankan program keagamaan dan social kemasyarakatan dan belum berfokus mengembangkan harta wakaf ke arah yang lebih produktif.
\end{abstract}

Kata kunci : Wakaf; Manajemen; Produktif. 


\section{Pendahuluan}

Indonesia adalah negara dengan populasimayoritas muslim terbesar di dunia. Fakta ini seringkali membuat kita berbangga sebagai umat muslim namun di sisi lain kecewa karena kesadaran pemerintah dan masyarakat terutama yang muslimterkait pengelolaan keuangan sosial islam sangat kurang diperhatikan, terutama wakaf. Padahal potensi wakaf terutama wakaf uang dan tanah apabila dimaksimalkan nilai valuasinya mencapai lebih dari Rp 2000 triliun (Hiyanti et al., 2020). Nilai tersebut sangat fantastis untuk hanya satu dari sekian banyak sektor keuangan social islam yang lain dan apabila ada kesadaran dari masyarakat muslim untuk memaksimalkannya maka bukan tidak mungkin Indonesia akan menjadi negara yang paling makmur karena memaksimalkan potensi tersebut.

Menurut tinjauan pemikiran ekonomi, wakaf menjadi sarana dalam mengembangkan harta produktif demi memberdayakan masyarakat sehingga hasilnya bisa dimanfaatkan oleh yang berhak menerimanya. Wakaf wajib menjadi lahan produktif supaya hasil dan manfaatnya dapat terus dirasakan. Namun pada realitasnya, di Indonesia wakaf masih identik dengan wakaf tanah dan bangunan. Berdasarkandata dari BWI Indonesia memiliki tanah wakaf seluas 4.359.443.170 meter persegi yang tersebar di 435.768 tempat, tetapi tanah wakaf tersebut hanya dimanfaatkan untuk pembangunan tempat ibadah sekitar $80 \%$. Dengan demikian dapat dikatakan bahwa pengelolaan tanah wakaf dalam sektor produktif belum tercapai (Hiyanti et al., 2020).

Berdasarkan jenis pengelolaannya, tanah wakaf dikelola oleh tiga macam tipe nazhir, diantaranya yaitu : 1) Pengelolaan wakaf secara tradisional, yaitu dana wakaf yang dikelola dan ditempatkan hanya bertujuan untuk murni ibadah semata. Misalnya untuk membangun masjid, kuburan, musala dan sekolah. 2) Pengelolaan wakaf secara semi tradisional, yakni harta wakaf dikelola masih dengan cara tradisional, tetapi para pengelola wakaf sudah mulai paham dalam pengembangan harta wakaf dengan cara yang lebih produktif dengan namun tingkat kemampuan dan manajerial yang masih terbatas. 3) Pengelolaan wakaf secara professional, yaitu nadzir diwajibkan agar bisa memaksimalkan harta wakaf untuk hal-hal yang lebih produktif lagi dan pengelolaannya dilakukan secara professional dan mandiri (Rahmania et al., 2020).

Tipe nazhir yang paling mendominasi di Indonesia dari ketiga macam tipe nazhir yang telah disebutkan diatas, yaitu tipe pertama yakni nazhir yang masih mengelola harta wakaf secara tradisional (Triyanta \& Zakie, 2014).Padahal berdasarkan data BWI luas tanah wakaf di Indonesia mencapai 4.359.443.170 $\mathrm{m}^{2}$ yang tersebar di seluruh wilayah provinsi. Diantara jumlah tersebut tanah wakaf yang sudah bersertifikat yaitu 287.160 lokasi dan yang belum bersertifikat sekitar 148.447, sehingga jumlah harta wakaf yang sudah bersertifikat lebih dominan dibandingkan yang belum bersertifikat. Namun sayangnya pengelolaannya masih dominan dilakukan secara tradisional (Badan Wakaf Indonesia (BWI), n.d.).

Harta benda wakaf di kabupaten Gowa, tepatnya di kelurahan Jene Tallasa kebanyakan digunakan untuk membangun masjid. Berdasarkan data Departemen Agama mencatat bahwa luas tanah di Kelurahan Jene Tallasa yang digunakan untuk membangun masjid adalah $2.192 \mathrm{~m}$ yang tersebar di 8 lokasi(Siwak Kemenag RI, n.d.). Padahal menurut Sayyi Baqid bahwa segala macam benda yang bersifat tetap, maupun bergerak seperti perlengkapan rumah, bukubuku, mashahif, senjata, kendaraan dan sebagainya 
dapat dijadikan sebagai objek wakaf bahkan benda yang diperdagangkan dan dimanfaatkan, juga boleh dijadikan sebagai objek wakaf(Naim, 2018).

Berdasarkan informasi tersebut di atas, maka sepatutnya pengelolaan tanah wakaf baik di Indonesia ataupun yang terdapat di kabupaten Gowa bisa digunakan secara produktif bukan cuma diperuntukkan buat membangun masjid tetapi pula bisa dikelola sesuai dengan kebutuhan masyakat di masa perkembangan seperti sekarang ini. Serta pula masih banyaknya warga yang tidak mengerti tentang wakaf itu sendiri sehingga butuh diadakan sosialisasi supaya warga bisa mengerti serta bisa merealisasikannya guna meningkatan pembangunan di kelurahan Jene Tallasa pada khusunya dan di Indonesia pada Umumnya. Berdasarkan masalah tersebut, penulis tertarik untuk melakukan penelitian yang berjudul "Analisis Manajemen Pengelolaan Wakaf Masjid Raodhatul Jannah Kelurahan Jene Tallasa Kabupaten Gowa”.

\section{KAJIAN LITERATUR}

Secara harfiah, kata wakaf berasal dari bahasa Arab yaitu waqf asalnya dari akar kata waqafa yang berarti menahan, diam di tempat, berhenti atau berdiri. Kata waqafayaqifu-waqfan sejalan dengan kata habasa-yahbisu-tahbisan artinya terhalang untuk menggunakan. Kata waqf dalam bahasa Arab mengandung arti menahan harta untuk diwakafkan, tidak dipindahmilikkan (Isfandiar, 2008). Sedangkan menurut istilah syara, menurut Muhammad Jawad Mughniyah dalam Fiqih Lima Mazhab mengatakan, wakaf adalah sejenis pemberian yang pelaksanaannya dilakukan dengan jalan menahan (pemilikan) asal, lalu menjadikan manfaatnya berlaku umum. Yang dimaksudkan dengan ialah menahan barang yang diwakafkan itu agar tidak diwariskan, digunakan dalam bentuk dijual, dihibahkan, digadaikan, disewakan, dipinjamkan, dan sejenisnya. Sedangkan cara pemanfaatannya adalah dengan menggunakannya sesuai dengan kehendak pemberi wakaf tanpa imbalan. (Khoerudin, 2018)

Undang-Undang Nomor 41 Tahun 2004 mengartikan wakaf sebagai perbuatan hukum wakif dalam memisahkan dan menyerahkan sebagian harta benda miliknya untuk digunakan selamanya atau untuk jangka waktu tertentu sesuai dengan kepentingan guna keperluan ibadah atau kesejahteraan umum menurut syari'at (Undang-Undang Nomor 41 Tahun 2004, 2004). Dalam hukum Islam untuk terwujudnya wakaf harus dipenuhi rukun dan syaratnya. Rukun wakaf menurut jumhur ulama ada empat, yaitu: (1) wakif, (2) benda yang diwakafkan, (3) mauquf 'alaih (penerima wakaf/Nazir), (4) ikrar (pernyataan) wakaf. Dalam UU No. 41/2004 tentang Perwakafan (pasal 6), selain empat unsur di atas dimasukkan juga sebagai rukun wakaf: peruntukan harta benda wakaf dan jangka waktu wakaf. Untuk orang yang berwakaf disyaratkan: (a) orang merdeka, (b) harta itu milik sempurna dari orang yang berwakaf, (c) baligh dan berakal, (d) cerdas (Munir, 2015).

Dalil yang menjadi dasar disyariatkannya ibadah wakaf bersumber dari pemahaman tafsir ayat Al-Qur'an dan Hadits. Akan tetapi, tidak terdapat ayat Al-Qur'an yang secara jelas dan gamblang menjelaskan tentang anjuran berwakaf (Nissa, 2017).

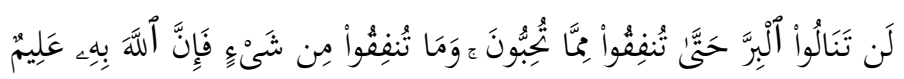

Kamu sekali-kali tidak sampai kepada kebajikan (yang sempurna), sebelum kamu menafkahkan sehahagian harta yang kamu cintai. dan apa saja yang kamu nafkahkan Maka Sesungguhnya Allah mengetahuinya. (Ali Imran:92) 


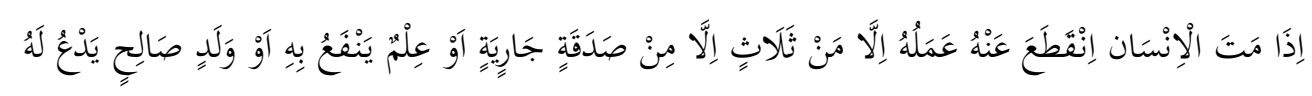

Apabila manusia telah meninggal dunia, maka putuslah amalnya kecuali tiga perkara: sedekah jariyah, ilmu yang bermanfaat dan anak-anak shaleh yang mendoakan orangtuanya" (HR. Muslim)

Harta benda wakaf yang diwakafkan dapat berupa benda tidak bergerak dan benda bergerak. Adapun benda tidak bergerak meliputi (Undang-Undang Nomor 42 Tahun 2006, 2006):

- Hak atas tanah sesuai dengan ketentuan peraturan perundang-undangan yang berlaku baik yang sudah maupun yang belum terdaftar.

- Bangunan atau bagian bangunan yang berdiri di atas tanah sebagaimana dimaksud pada huruf a.

- Tanaman dan benda lain yang berkaitan dengan tanah.

- Hak milik atas satuan rumah susun sesuai dengan ketentuan peraturan perundang-undangan yang berlaku.

- Benda tidak bergerak lain sesuai dengan ketentuan syariah dan peraturan perundang-undangan yang berlaku.

Adapun harta bergerak yang tidak bisa habis karena dikonsumsi meliputi (Undang-Undang Nomor 42 Tahun 2006, 2006):

- Uang;

- Logam mulia;

- Surat berharga;

- Kendaraan;

- Hak atas kekayaan intelektual;

- Hak sewa; dan

- Benda bergerak lain sesuai dengan ketentuan syariah dan peraturan perundang-undangan yang berlaku.

Masjid adalah sebuah bangunan, tempat beribadah umat muslim yang digunakan oleh umat muslim sebagai tempat dilaksanakannya shalat berjama'ah (Syahidin, 2003). Kata masjid terulang sebanyak 28 kali di dalam Al-Quran. Secara etimologi, kata tersebut diambil dari akar kata sajada-sujud yang artinya patuh, taat serta tunduk dengan penuh hormat dan takzim (Al Ayubi, 2008). Fungsi masjid yakni sebagai baitullah, artinya tempat suci turunnya rahmat Allah SWT dan malaikat Allah karena dalam pandangan Islam masjid merupakan tempat terbaik di muka bumi. Masjid merupakan tempat umat Islam menemukan ketenangan dan kesucian jiwa yang di dalamnya terdapat majelis dan forum terhormat (Auliyah, 2014).

\section{Metode Penelitian}

Penelitian ini merupakan penelitian lapangan (field research) dengan pendekatan kualitatif. Menurut Sugiyono penelitian kualitatif adalah penelitian yang digunakan untuk 
meneliti pada kondisi objek alamiah, dimana peneliti merupakan instrumen kunci(Sugiyono, 2005). Selain itu, penelitian ini bersiafat deskriprif, yaitu penelitian yang semata-mata hanya menggambarkan (mendeskripsikan) keadaan dan kejadian atas suatu objek yang diuraikan secara lengkap, rinci dan jelas (Suryabata, 1990).

Jenis data yang digunakan dalam penelitian ini adalah data primer dan data sekunder. Data primer merupakan data yang didapatkan langsung dari subjek penelitian dimana data tersebut diambil langsung oleh peneliti kepada informan melalui wawancara. Sedangkan data sekunder didapatkan melalui buku, jurnal, dan artikel lainnya yang memiliki keterkaitan dengan objek penelitian (Meleong, 2006).

\section{Hasil dan Pembahasan}

Kelurahan Jene Tallasa merupakan salah satu dari 4 kelurahan dan 12 desa yang ada di kecamatan Pallangga dengan luas wilayah sebesar $3.220 .000 \mathrm{~m}^{2}$. Kelurahan Jene Tallasa berbatasan di sebelah utara dengan desa Tetebatu, disebelah selatan dengan desa Bungaejaya dan desa Julukanaya dan disebelah timur dengan desa Parang Banoa. Jumlah penduduk kelurahan Jene Tallasa sebanyak 17.696 jiwa menjadikan kelurahan Jene Tallasa sebagai salah satu kelurahan dengan jumlah penduduk terbesar di kabupaten Gowa dan hanya berada di urutan kedua setelah desa Bontoala sebagai desa dengan penduduk terbesar di kecamatan Pallangga.

Masjid Raodhatul Jannah merupakan masjid yang terletak di kompleks BTN. Jene Ci'nong Kelurahan Jene Tallasa Kecamatan Pallangga Kabupaten Gowa. Masjid ini didirikan pada tahun 2000 yang mana awalnya merupakan tanah kosong kemudian diwakafkan pada tahun 1998 dan dibangunkan bangunan masjid melalui sumbangan uang dan tenaga dari warga sekitar. Sempat terjadi beberapa kali renovasi dan yang paling terbaru sekaligus renovasi yang terbesar dalam rangka memperluas area masjid terjadi pada tahun 2018. Masjid ini belum memiliki sertifikat wakaf namun sudah ada upaya yang pernah dilakukan oleh Kementerian Agama yang datang untuk mendata setiap masjid termasuk masjid ini dan akan diberikan sertifikat gratis. Namun, menurut pengurus masjid sampai sekarang belum ada kelanjutan dari persoalan tersebut.

Kantor Urusan Agama (KUA) Kecamatan Pallangga tidak memiliki data terkait sejarah berdirinya KUA tersebut. Begitu juga dengan data mutakhir terkait harta wakaf yang ada di kelurahan Jene Tallasa. Saat mengadakan penelitian, tidak ada satupun pegawai KUA yang bisa memberikan informasi mengenai sejarah berdirinya KUA dengan alasan bahwa mereka memang tidak mengetahuinya. Begitu juga dengan data mutakhir terkait harta wakaf, namun mereka memberikan solusi untuk berpatokan kepada situs Sistem Informasi Wakaf (SIWAK) yang dikelola oleh Kementerian Agama.

Adapun penelitian ini mengambil 4 informan yang berprofesi sebagai Pengurus Masjid dan 1 informan yang berprofesi sebagai Staf KUA Kecamatan Pallangga Kabupaten Gowa. Peneliti juga memasukkan data diri baik nama, umur dan alamat para subjek yang akan diteliti. Harta benda wakaf di kelurahan Jene Tallasa kebanyakan berupa tanah yang peruntukannya hanya untuk dibangunkan sebuah masjid. Adapun KUA kecamatan Pallangga yang dibawah naungan Kementerian Agama dalam hal ini untuk mengurusi wakaf jika ada yang mau mendaftarkan harta benda wakafatau melakukan prosedur pergantian/pengangkatannadzir dengan melalui mekanisme yang cukup mudah. Hal itu sesuai dengan apa yang disampaikan oleh Bapak H. Ardan Ilyas: 
"Jadi mekanisme pendafatarannya yaitu mengambil blanko pendaftaran di KUA kemudian diisi dan dilengkapi segala persyaratannya, baik itu nadzir, wakif kemudian dilengkapi dengan sertifikat tanah yang akan diwakafkan. Selanjutnya mengambil surat keterangan di kantor lurah/desa. Kemudian wakif membuat surat pernyataan penyerahan tanah yang akan diwakafkan dan terakhir segala data dan berkas terkait harta yang akan diwakafkan diserahkan ke KUA untuk didaftarkan dengan membawa 2 saksi yang juga membawa fotokopi KTP-nya masing-masing.Prosedur pengesahan nadzir yang berjumlah 5 orang yang meliputi ketua, sekretaris, bendahara dan 2 anggota. Setelah mereka bertanda tangan di atas materai kemudian dibuatkan 3 rangkap arsip untuk KUA, nadzir dan untuk Kementerian Agama Kabupaten Gowa.”(Ilyas, 2021)

Tabel 1Data Informan Penelitian

\begin{tabular}{llll}
\hline No & Nama & Umur & Alamat \\
\hline 1 & Muchtar Hasan & 60 tahun & BTN Jene Cinong \\
2 & Rabuddin, S.Pd & 62 tahun & BTN Jene Cinong \\
3 & Abd. Muis, S.Pd, MM & 49 tahun & BTN Jene Cinong \\
4 & Subair, S.Sos & 52 tahun & BTN Jene Cinong \\
5 & H. Ardan Ilyas, S.Pd.i., M.A & 48 tahun & Cambaya, Jene Tallasa \\
\hline \multicolumn{4}{r}{ Sumber : data diperoleh melalui wawancara }
\end{tabular}

Data ini diperoleh melalui wawancara di lapangan. Peneliti mewawancarai lima informan diantaranya satu informan sebagai Staf KUA Kecamatan Pallangga dan empat informan sebagai Pengurus Masjid Raodhatul Jannah. Informan yang paling muda berumur 48 tahun dan yang paling tua berumur 62 tahun.

Adapun rumusan pertanyaan yang peneliti tanyakan kepada informanpertama dalam hal ini Staf KUA Kecamatan Pallangga, pertamaapa kendala yang sering terjadi atau mungkin mempersulit pengurusan wakaf. Kedua, apakah sebelumnya ada sengketa terhadap tanah yang telah diwakafkan. Ketiga, Bagaimana upaya KUA dalam melakukan sosialisasi kepada masyarakatterkait perwakafan. Rumusan pertanyaan yang peneliti tanyakan kepada informan kedua dalam hal ini Pengelola Masjid Raodhatul Jannah, pertamasebelum menjadi masjid apakah harta wakaf ini masih berupa tanah atau bangunan masjid yang sudah jadi. Kedua, apakah harta wakaf ini sudah bersertifikat atau belum memiliki sertifikat. Ketiga, apakah ada upaya dari pengurus masjid untuk mengurus sertifikat wakaf agar terjamin legalitasnya. Keempat, program-program apa saja yang dilaksanakan untuk mengembangkan harta wakaf ini.

\section{Petugas KUA}

H. Ardan Ilyas, S.Pd.i., M.A selaku Petugas KUA Kecamatan Pallangga mengatakan bahwa selama ini tidak ada kendala yang berarti yang dialami oleh petugas KUA dalam mengurusi harta wakaf yang akan didaftarkan ke KUA. Namun yang lebih banyak kendala itu di masyarakat. Alasannya karena tanahnya tidak memiliki sertifikat, masalah perbedaan persepsi dalam keluarga terkait harta yang akan diwakafkan, pemahaman masyarakat terkait wakaf masih belum baik. Sebagaimana yang disampaikan oleh beliau bahwa:

"Sebenarnya kendala tidak terdapat di KUA, melainkan di masyarakat. Biasanya ada keluarga yang bersedia hartanya diwakafkan namun ada saudara mereka yang menolak. Ada Nenek yang mewakafkan hartanya, dikemudian hari cucunya datang menuntut balik."(Ilyas, 2021) 
H. Ardan Ilyas juga mengingatkan betapa pentingnya legalitas sebuah harta wakaf agar dikemudian hari tidak terjadi hal tersebut. Mendaftarkan harta wakaf di KUA juga sama sekali tidak dipungut biaya alias gratis. Sebagaimana yang disampaikan oleh beliau bahwa:

"Makanya memang perlu adanya legalitas dari KUA sebagai legalitas formal yang menandakan bahwa harta tersebut sah merupakan harta wakaf. Perlu diketahui juga bahwa disini tidak dipungut biaya dalam pengurusan harta wakaf."'(Ilyas, 2021)

H. Ardan Ilyas sebagai petugas KUA mengatakan bahwa yang perlu didorong kepada masyarakat mengenai harta benda wakaf itu bukan cuma tanah, masjid, sekolah melainkan juga kuburan. Harta wakaf paling banyak berupa tanah dan masjid namun tidak semua masjid juga memiliki sertifikat wakaf karena kendala yang telah disebutkan diatas. Sebagaimana yang disampaikan oleh beliau bahwa:

"Harta wakafyang paling banyak yaitu tanah, masjid dan sekolah namun kurang yang mewakafkan lahan untuk pekuburan. "(Ilyas, 2021)

Pelatihan kepada nadzir belum pernah terlaksana, namun nadzir hanya diberikan pengarahan dan bimbingan terkait perwakafan di KUA tersebut. Sosialisasi terkait wakaf juga dilaksanakan oleh KUA kepada imam-imam masjid di desa dan kelurahan serta sosialisasi melalui ceramah-ceramah di setiap masjid mengenai pentingnya perwakafan dan legalitasnya. Sebagaimana yang disampaikan oleh beliau bahwa:

"Sampai sekarang belum ada pelatihan kepada nadzir namun hanya diberikan bimbingan dan pengarahan terkait perwakafan. Sosialisasi sering diadakan khususnya kepada imam di seluruh desa dan kelurahan kemudian diteruskan lagi kepada masyarakat melalui ceramah agama. "(Ilyas, 2021)

\section{Pengelola Masjid}

Abd. Muis, S.Pd., MM selaku Pengelola Masjid Raodhatul Jannah mengatakan bahwa awalnya masjid Raodhatul Jannah merupakan sebuah tanah kosong yang kemudian diatasnya didirikan sebuah masjid. Tanah ini merupakan tanah wakaf dari pemilik developher perumahan PT Inggrit Melati yaitu Bapak Roni Bonang dan Ibu Inggrit Melati. Sebagaimana yang disampaikan oleh beliau bahwa:

"Dulu saya bekerja sebagai karyawan di PT Inggrit Melati dan pemilik perusahaannya yang mewakafkan tanah tersebut."(Abd. Muis, 2021)

Muchtar Hasan selaku Pengelola Masjid Raodhatul Jannah mengatakan bahwa tanah tersebut diwakafkan pada tahun 1998 dan dibangunkan sebuah masjid pada tahun 2000. Namun, masjid tersebut belum memiliki sertifikat wakaf sampai sekarang dikarenakan pewakaf (wakif) sudah meninggal dunia dan keluarganya terakhir diketahui bermukim di Jakarta Selatan. Sebagaimana yang disampaikan oleh beliau bahwa:

"Saya menetap disini mulai tahun 1997 dan setahun kemudian tanah tersebut diwakafkan oleh pemilik Developher perumahan. Tahun 2000 baru kemudian didirikan sebuah masjid hasil kerja keras warga. Pewakafnya sudah meninggal jadi susah untuk mengurus sertifikasinya"(Muchtar Hasan, 2021)

Rabuddin, S.Pd selaku Pengelola Masjid Raodhatul Jannah mengatakan bahwa Kementerian Agama Kabupaten Gowa pernah berkunjung sekaligus mendata terkait harta wakaf yang belum tersertifikasi karena akan dibuatkan sertifikat wakaf gratis bagi masjid 
yang belum memiliki sertifikat sebagai harta wakaf tidak terkecuali masjid Raodhatul Jannah. Sebagaimana yang disampaikan oleh beliau bahwa:

"Pernah ada wacana akan dibuatkan sertifikat gratis oleh Kemenag, kami sudah lengkapi data-data yang harus dimasukkan namun sampai sekarang belum ada kelanjutan terkait hal itu. "(Rabuddin, 2021)

Subair, S.Sos selaku Pengelola Masjid Raodhatul Jannah mengatakan bahwa pengelolaan tanah wakaf di masjid Raodhatul Jannah memiliki program dan mengadakan berbagai kegiatan-kegiatan keagamaan dan social kemasyarakatan yang dilaksanakan oleh pengurus masjid Raodhatul Jannah diantaranya majelis taklim dan pengajian rutin bulanan, TPA, LDK untuk Remaja Masjid, buka puasa bersama pada bulan Ramadhan, pusat informasi masyarakat tentang kegiatan penimbangan balita dan posyandu serta kegiatan bermanfaat lain bagi masyarakat. Sebagaimana yang disampaikan oleh beliau:

"Banyak kegiatan bermanfaat yang dilaksanakan di masjid ini seperti majelis taklim dan pengajian rutin bulanan, TPA, LDK untuk Remaja Masjid, buka puasa bersama pada bulan Ramadhan, pusat informasi masyarakat tentang kegiatan penimbangan balita dan posyandu serta kegiatan bermanfaat lainnya." (Subair, 2021)

Sejalan dengan informasi yang didapatkan melalui wawancara dengan beberapa informan yang telah disebutkan diatas, menurut pengamatan peneliti pemberdayaan tanah wakaf ini masih sebatas untuk keagamaan dan social kemasyarakatan. Belum terdapat upaya pemberdayaan tanah wakaf kearah yang lebih produktif. Tanah wakaf yang belum tersertifikasi hingga saat ini merupakan dampak praktek perwakafan yang dilakukan oleh masyarakat secara lisan dengan dalih asas saling percaya dan mengabaikan prosedur yang ada dalam peraturan perundang-undangan.

\section{KESIMPULAN}

Harta benda wakaf yang di wakafkan di Kelurahan Jene Tallasa kebanyakan merupakan tanah atau benda tidak bergerak. Problematika pengelolaan wakaf di masjid Raodhatul Jannah adalah tanah wakafnya masih belum memiliki sertifikat karena adanya kendala yaitu pewakaf telah meninggal dunia dan keluarga pewakaf yang terakhir diketahui tinggal di Jakarta Selatan sekarang keberadaannya tidak diketahui. Pengelola masjid kebanyakan hanya menjalankan program keagamaan dan social kemasyarakatan dan belum berfokus mengembangkan harta wakaf ke arah yang lebih produktif. Proses perwakafan yang dilakukan di Kelurahan Jene Tallasa kebanyakan diperuntukkan untuk pembangunan sarana ibadah sehingga hasil dari harta wakaf yang dikelola saat ini dikategorikan belum maksimal karena belum dikelola secara produktif.

\section{REFERENSI}

Abd. Muis. (2021). Pengelola Masjid Raodhatul Jannah. Wawancara.

Al Ayubi, U. S. (2008). Peran dan Fungsi Masjid bagi Umat Islam. Buletin Al-Arham. Edisi, 5.

Auliyah, R. (2014). Studi Fenomenologi Peranan Manajemen Masjid At-Taqwa dalam Pemberdayaan Ekonomi Masyarakat Bangkalan. Competence: Journal of Management Studies, 8(1). 
Badan Wakaf Indonesia (BWI). (n.d.). Data Tanah Wakaf Seluruh Indonesia. Situs Resmi Badan Wakaf Indonesia. Retrieved May 25, 2021, from https://bwi.or.id/index.php/en/tentang-wakaf/data-wakaf/data-wakaf-tanah.html

Hiyanti, H., Afiyana, I. F., \& Fazriah, S. (2020). Potensi Dan Realisasi Wakaf Uang di Indonesia Tahun 2014-2018. Jurnal Ilmiah MEA (Manajemen, Ekonomi, \& Akuntansi), 4(1), 77-84.

Ilyas, H. A. (2021). Staf KUA Kecamatan Pallangga. Wawancara.

Isfandiar, A. A. (2008). Tinjauan Fiqh Muamalat dan Hukum Nasional tentang Wakaf di Indonesia. La_Riba: Jurna; Ekonomi Islam, 2(1), 51-73.

Khoerudin, A. N. (2018). Tujuan Dan Fungsi Wakaf Menurut Para Ulama Dan Dan Undang-Undang Di Indonesia. Tazkiya, 19(02), 1-10.

Meleong, L. J. (2006). Metode Penelitian Kualitatif Edisi Revisi (Cet. Ke 22). PT REMAJA ROSDAKARYA.

Muchtar Hasan. (2021). Pengelola Masjid Raodhatul Jannah. Wawancara.

Munir, A. S. (2015). Optimalisasi Pemberdayaan Wakaf Secara Produktif. Jurnal Ummul Qura, 6(2).

Naim, A. H. (2018). Pengembangan Objek Wakaf dalam Fiqih Islam dan Hukum Positif di Indonesia. ZISWAF: Jurnal Zakat Dan Wakaf, 4(2), 245-262.

Nissa, C. (2017). Sejarah, Dasar Hukum dan Macam-Macam Wakaf. Tazkiya, 18(02), 205-219.

Rabuddin. (2021). Pengelola Masjid Raodhatul Jannah. Wawancara.

Rahmania, N., Jannah, W., \& Sofyan, A. S. (2020). Fenomena Pengelolaan dan Pemberdayaan Harta Benda Wakaf di Kecamatan Mamajang Kota Makassar. Management of Zakat and Waqf Journal (MAZAWA), 2(1), 78-100.

Undang-Undang Nomor 41 Tahun 2004, Pub. L. No. 41 (2004).

Undang-Undang Nomor 42 Tahun 2006, Pub. L. No. 42 (2006).

Siwak Kemenag RI. (n.d.). Data Tanah Wakaf.

Subair. (2021). Pengelola Masjid Raodhatul Jannah. Wawancara.

Sugiyono, P. (2005). Memahami penelitian kualitatif. Alfabeta.

Suryabata, S. (1990). Metodologi Penelitian. Rajawali Pers.

Syahidin. (2003). Pemberdayaan Umat Berbasis Masjid. Alfabeta.

Triyanta, A., \& Zakie, M. (2014). Problematika Pengelolaan Tanah Wakaf: Konsep Klasik dan Keterbatasan Inovasi Pemanfaatannya di Indonesia. Jurnal Hukum IUS QUIA IUSTUM, 21(4), 583-606. 